\title{
Oxidative stress in osteomyelitis and burns: Specific features of its role in development of pathology
}

\author{
Andrew K. Martusevich ${ }^{*}$, Valery I. Zagrekov, Ksenia L. Belyaeva, Alexander S. Pushkin, Anna G. Soloveva
}

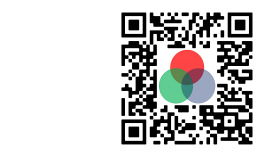

Use your smartphone to scan this QR code and download this article

\begin{abstract}
Introduction: The purpose of this study was to evaluate and compare the features of the initiation and development of oxidative stress in patients with osteomyelitis and burns. Methods: We studied the oxidative metabolism of blood of 20 healthy subjects (controls), 15 patients with burns, and 18 patients with chronic osteomyelitis. All patients included in the second group had thermal burns of the I-II-III degree in trunk and limbs on an area of 31 - $80 \%$ of the body surface without thermal inhalation trauma. After standard sample preparation, a wide range of parameters of oxidative metabolism was determined in the blood. The intensity of free radical processes in blood plasma and red blood cells, and the total antioxidant activity was evaluated by Fe-induced biochemiluminescence. The concentration of malonic dialdehyde in blood plasma and red blood cells was determined. The level of diene and triene conjugates and Schiff bases was determined spectrophotometrically using reagent kits. The catalase and superoxide dismutase activities in the red blood cells of patients from each of the groups was also determined. Results: We showed that in osteomyelitis, which is a long-lasting process, changes in the balance of free radical generation and activity of the antioxidant system were compensatory and mostly related to changes in blood plasma. On the contrary, in burn victims, oxidative stress signs had a maladaptive character. They were seen in blood plasma and red blood cells, and accompanied by a pronounced depletion of enzyme antioxidant system reserves. Conclusion: Our study demonstrate the role of oxidative stress in patients with burns and chronic osteomyelitis, and demonstrate some specific features leading to formation of disease pathology. Such features of oxidative stress may be useful in future design of new approaches to correct the pathology of diseases.

Key words: oxidative stress, burns, osteomyelitis, free radical processes, antioxidant system
\end{abstract}

Privolzhsky Research Medical University, Nizhny Novgorod, Russia

\section{Correspondence}

Andrew K. Martusevich, Privolzhsky Research Medical University, Nizhny Novgorod, Russia

Email: cryst-mart@yandex.ru

History

- Received: Feb 03, 2021

- Accepted: Mar 25, 2021

- Published: Mar 31, 2021

DOI : 10.15419/bmrat.v8i3.667

\section{Check for updates}

\section{Copyright}

( ) Biomedpress. This is an openaccess article distributed under the terms of the Creative Commons Attribution 4.0 International license.

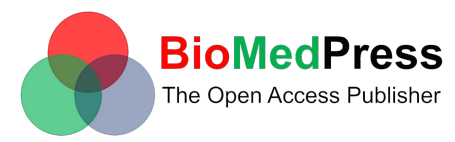

a greater extent, this applies to surgical diseases, including traumatological and orthopedic pathologies. A few studies have been recently devoted to this issue. Thus, there is evidence of the involvement of oxidative stress in the pathogenesis of thermal trauma ${ }^{18-21}$ and chronic post-traumatic inflammatory processes, such as osteomyelitis ${ }^{22-24}$. However, there is no information about the formation and progression of oxidative stress in these diseases. The purpose of the study herein was to conduct a comparative evaluation and analysis of the features of the formation and development of oxidative stress in patients with osteomyelitis and burns.

\section{MATERIAL - METHODS}

\section{Patient and control groups}

We studied the oxidative metabolism of blood of 20 healthy subjects (control), 15 patients with burns, and 18 patients with chronic osteomyelitis. All patients included in the second group had thermal burns of the I-II-III degree in the trunk and/or limbs (on an area 
ranging from $31-80 \%$ of the body surface); these patients were absent of thermal inhalation trauma. After receiving the study participants' voluntary informed consent, blood samples from patients of the second and third groups were obtained at admission to the hospital. In patients with burns, blood samples were taken up to 4 days after the moment of injury.

\section{Laboratory assays}

After standard sample preparation, a wide range of parameters of oxidative metabolism was determined in the blood. In particular, the intensity of free radical processes in blood plasma and red blood cells, as well as the total antioxidant activity, were evaluated by Feinduced biochemiluminescence. In addition, the concentration of malonic dialdehyde in blood plasma and red blood cells was determined. The level of diene and triene conjugates, and of Schiff bases, was determined spectrophotometrically using reagent kits. Catalase and superoxide dismutase activities in the red blood cells of patients from each of the designated groups were also determined.

\section{Statistics}

The results were processed using the Statistica 6.0 program $^{13}$. All the data were processed using standard algorithms of descriptive statistics and were presented as Mean \pm SD. The Student's t-test was used for the detection of statistical differences ( $p<0.05$ was set as the statistical significance level).

\section{RESULTS}

It was discovered that the integral indicator of the intensity of free radical processes in blood plasma and red blood cells (the light sum of Fe-induced biochemiluminescence) showed intergroup differences (Figure 1).

Thus, there is a stimulation of free radical oxidation in the blood plasma of patients with burns and osteomyelitis. This trend is expressed equally $(+27.8 \%$ and $+27.1 \%$ relative to practically healthy people, respectively; $\mathrm{p}<0.05$ for both cases). On the contrary, in the group of patients with osteomyelitis in red blood cells, the indicator values does not differ from that of the control level. However, in severely burned patients, its moderate increase was recorded $(+8 \%$; $\mathrm{p}<0.05$ relative to practically healthy people). This indicates the presence of certain features of a shift in oxidative metabolism in the diseases under consideration.

Moreover, the variability of changes is manifested in the total antioxidant activity of blood plasma
(Figure 2). It should be noted that both burns and chronic osteomyelitis show a decrease in antioxidant potential of the plasma. Together with an increase in the intensity of free radical processes, this will allow us to record the formation of oxidative stress in both diseases. Simultaneously, the severity of the decrease in the total antioxidant activity is not the same. In particular, in osteomyelitis, the reduction in the indicator level is $20.4 \%$. In contrast, in patients with burns, a decrease in the parameter value was recorded by $7.8 \%$ ( $p<0.05$ for both cases compared to practically healthy people). Simultaneously, the antioxidant activity of blood plasma in severely burned patients is 1.16 times higher than in osteomyelitis $(\mathrm{p}<0.05)$.

Analysis of the level of malonic dialdehyde in blood plasma and red blood cells also allowed us to verify the specificity of the implementation of oxidative stress in burns and chronic osteomyelitis (Figure 3 and Figure 4). Indeed, in the blood plasma, the concentration of the secondary product of lipid peroxidation increases only in patients with chronic osteomyelitis (by $25.6 \%$ relative to the control group; $\mathrm{p}<0.05$ ), while in patients with burns, it remains at the level of practically healthy people (Figure 3).

On the contrary, the concentration of malonic dialdehyde in red blood cells increases in representatives of both groups (osteomyelitis and burns), but this trend is expressed differently (Figure 4). A more distinct increase in the red blood cell level of the compound was observed in the burn group (1.54-fold increase compared to healthy group; $\mathrm{p}<0.05)$ than in the chronic osteomyelitis group $(+39.1 \%$; $<<0.05)$. It should be noted that the concentration of malonic dialdehyde in burns is significantly higher than in osteomyelitis (by $10.5 \%$; $<0.05)$.

According to the assessment results of the level of other lipid peroxidation products, less significant changes were revealed (Figure 5). A moderate increase was found only for diene conjugates, and these changes were expressed almost equally in patients with burns and osteomyelitis $(+9.7$ and $+12.8 \%$ relative to the control group, respectively; $\mathrm{p}<0.05$ ).

We also evaluated the state of the enzyme antioxidant systems in the patient groups (Figure 6 and Figure 7). It was found that the pathologies had a multidirectional effect on the activity of erythrocyte superoxide dismutase (Figure 6). Thus, in chronic osteomyelitis, moderate activation of the enzyme was noted (by $10.6 \%$ relative to practically healthy people; $\mathrm{p}<0.05$ ). In patients with burns, there was a significant inhibition of the enzyme (by 20.3\%; p < 0.05).

Analysis of red blood cell catalase activity revealed activation only in chronic osteomyelitis (1.25-fold 


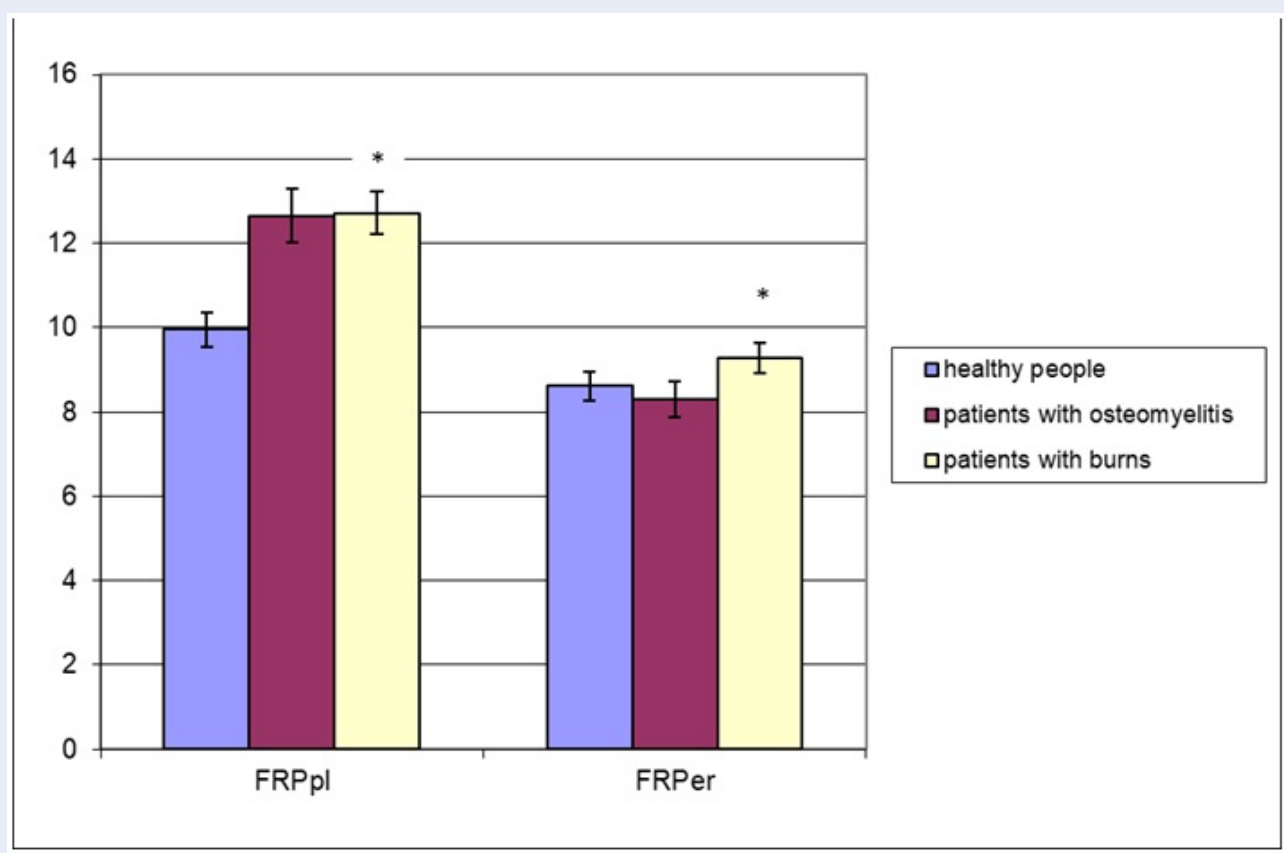

Figure 1: The intensity of free radical processes in blood plasma and erythrocytes in healthy people and patients with chronic osteomyelitis and burns ("**" - level of statistical differences to healthy people; $p<0.05$ ).

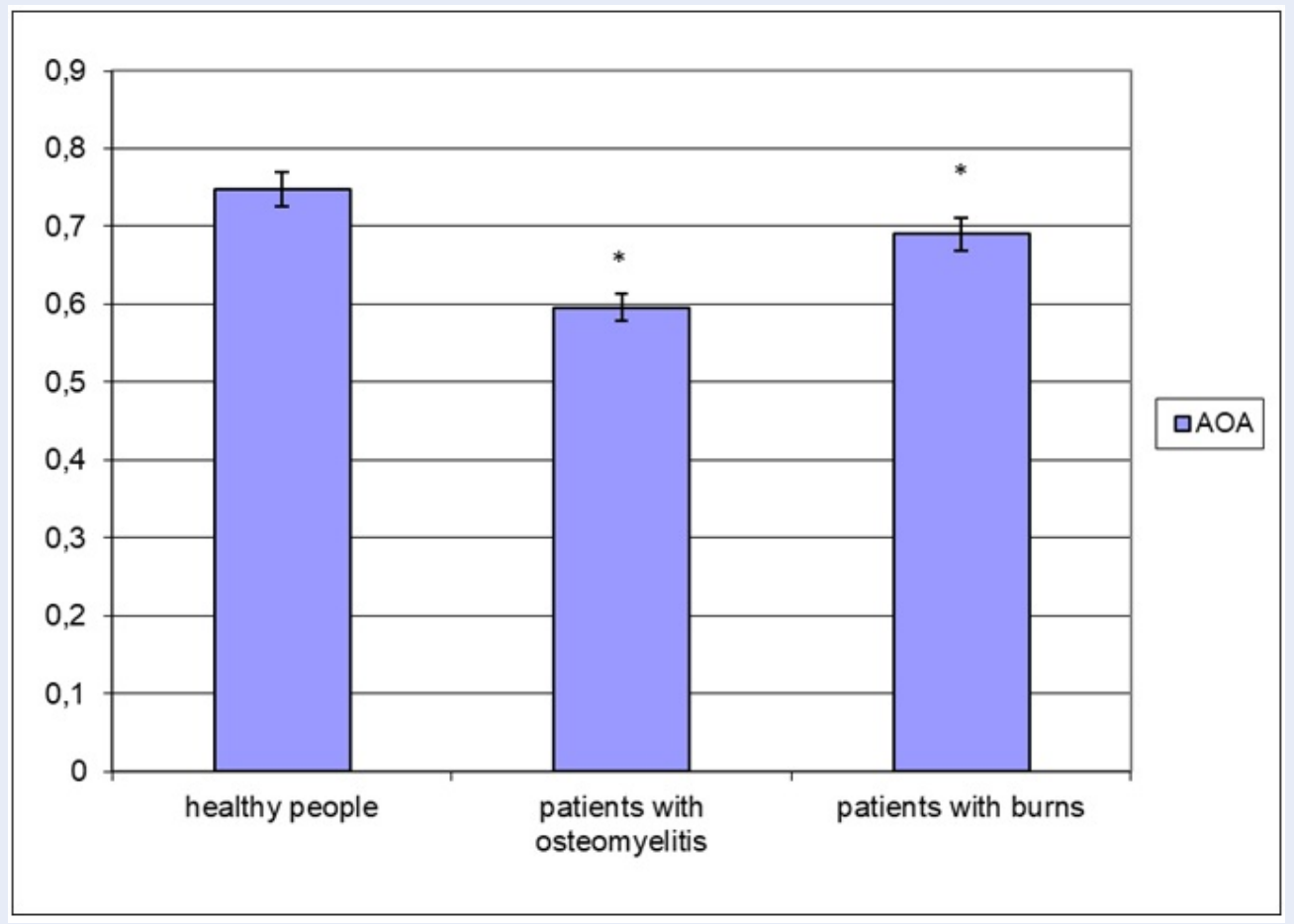

Figure 2: Total antioxidant activity in blood plasma and erythrocytes in healthy people and patients with chronic osteomyelitis and burns ("*" - level of statistical difference when compared to healthy people; $p<0.05$ ). 


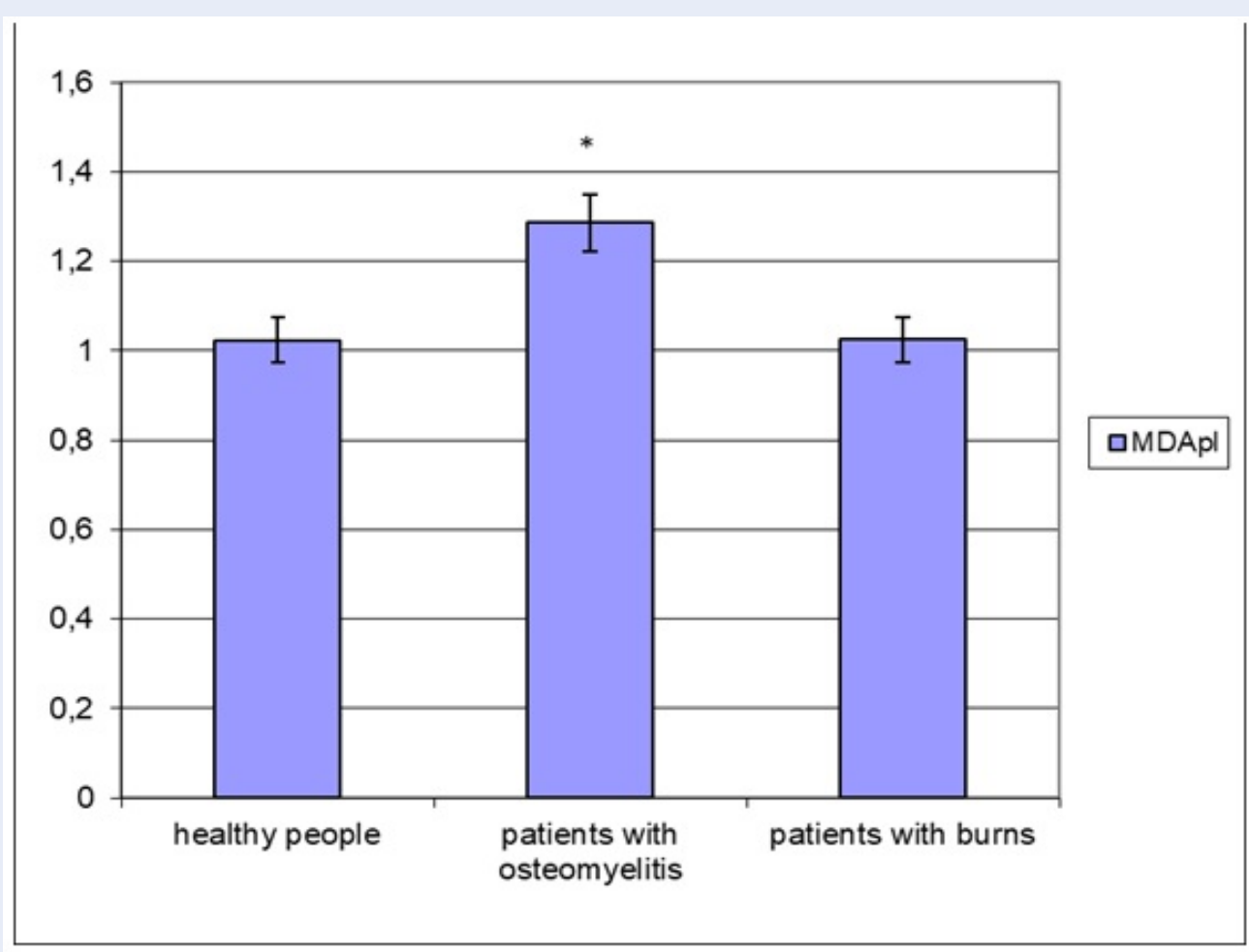

Figure 3: Malonic dialdehyde level in blood plasma in healthy people and patients with chronic osteomyelitis and burns ("*" - level of statistical differences to healthy people; $p<0.05$ ).

greater than that of the control group; $\mathrm{p}<0.05)$, while in severely burned patients, the enzyme's properties and function remained at the physiological level.

\section{DISCUSSION}

It is known that oxidative stress is a universal pathological process (syndrome) that develops in various diseases and conditions ${ }^{8-17}$. Simultaneously, there is relatively little information about the specificity of changes in the balance of free radical processes and antioxidant systems in blood and tissues formed within the framework of oxidative stress in specific pathologies ${ }^{1,4,5}$. Therefore, this study attempted to establish the features of specificity for oxidative stress in traumatic pathologies (e.g. burns and chronic osteomyelitis).

The study demonstrated the general signs and features of the implementation of oxidative stress in osteomyelitis and burns. Indeed, the presence of this syndrome in both pathological conditions was confirmed by the detection of characteristic laboratory shifts, including the intensification of free radical oxidation in the blood plasma, as well as suppression of its antioxidant reserves. These results confirm our previously published results ${ }^{18-25}$ and those of other authors $19,20,23,26,27$. At the same time, the persistent nature of these disorders is emphasized by the detection of increased levels of diene conjugates which increase about equally in patients with burns and osteomyelitis.

On the other hand, there are some features of oxidative stress in the evaluated pathological conditions. Particularly, we suggest that the changes are more related to free radical reactions occurring in the blood plasma in chronic osteomyelitis. This is evidenced by the absence of shifts in Fe-induced biochemiluminescence in the membranes of red blood cells in this pathology and a more pronounced decrease in the total antioxidant activity in blood plasma than in patients with burns. In addition, in osteomyelitis, an increase in the plasma concentration of malonic dialdehyde was observed, which was absent in severely burned patients. Finally, the synchronization of the pathological process in osteomyelitis contributes to the formation of compensatory rearrangements of the enzyme antioxidant system ${ }^{23,24}$, as evidenced by a moderate increase in the activity of erythrocyte superoxide dismutase and catalase. We assume that this circumstance is responsible for the lower severity of 


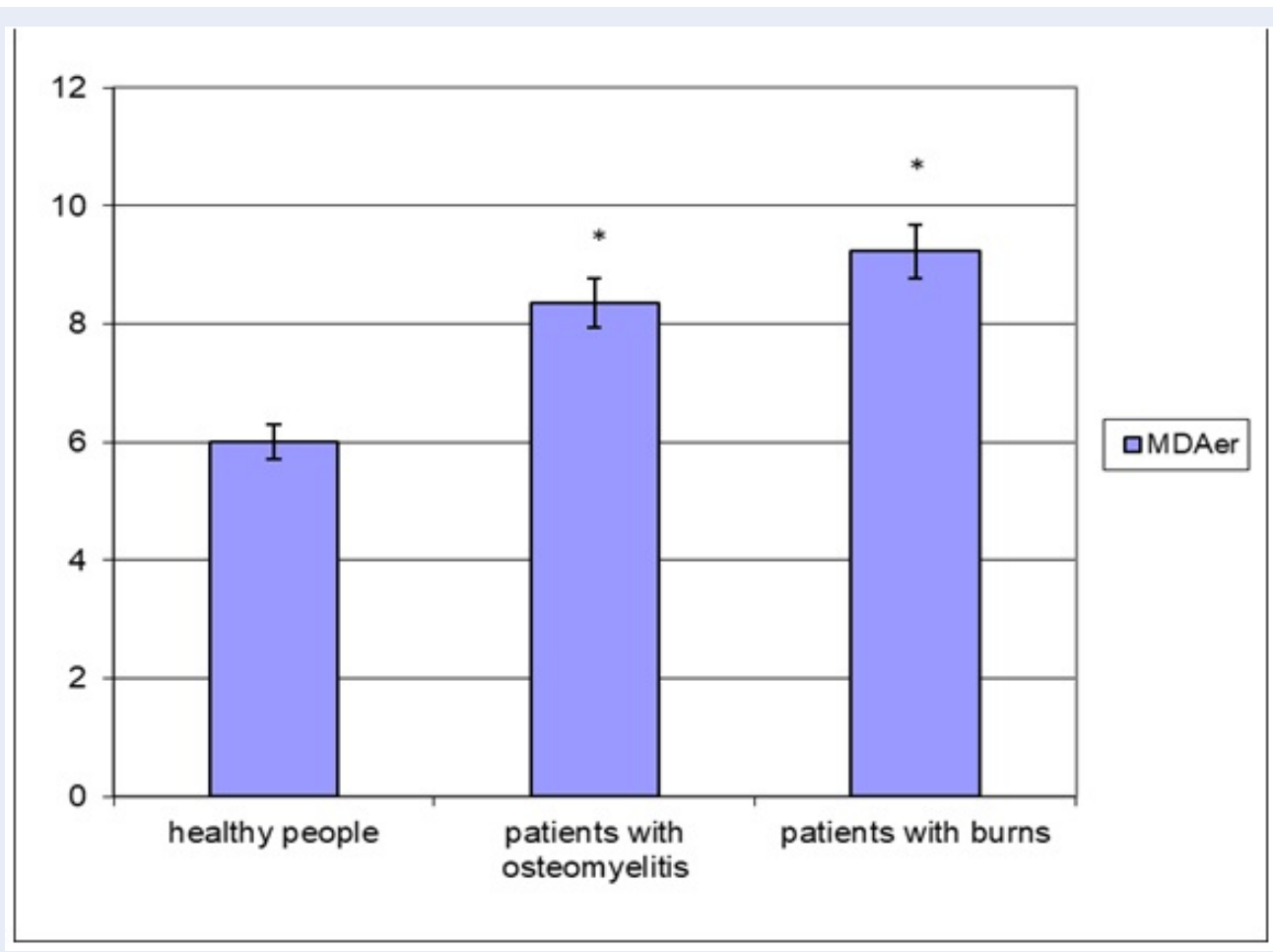

Figure 4: Malonic dialdehyde level in erythrocytes in healthy people and patients with chronic osteomyelitis and burns ("*" - level of statistical differences to healthy people; $p<0.05$ ).

oxidative metabolism changes in the red blood cells of patients with chronic osteomyelitis.

On the contrary, in burn victims, changes in free radical processes fully affect both blood plasma and red blood cells. This is indicated by a significant increase in the light sum of $\mathrm{Fe}$-induced biochemiluminescence as an integral indicator of the intensity of lipid peroxidation and other free radical reactions in blood plasma and red blood cells. Also, this pathological condition (burn) is characterized by a more pronounced increase in the red blood cell concentration of malonic dialdehyde, in combination with an increase in the level of diene conjugates, than in osteomyelitis. This may indicate that the process is active. In addition, it should be emphasized that an acute thermal burn injury does not involve the inclusion of compensatory mechanisms, in particular, enzyme antioxidant systems ${ }^{18,20,21,26,28}$. This leads to a rapid depletion of their reserves during the conditions of intensification of free radical formation. This is indicated by the inhibition of erythrocyte superoxide dismutase activity detected in burns, which ensures the formation of distinct signs of oxidative stress in the red blood cells of patients in this group.

\section{CONCLUSION}

The study herein enabled the verification of oxidative stress in patients with burns and chronic osteomyelitis. The specificity of the formation of the pathological syndrome (oxidative stress) was found. We have shown that in osteomyelitis, since it is a long-lasting process, changes in the balance of free radical generation and the activity of the antioxidant system are compensatory and mostly relate to changes in blood plasma. On the contrary, in burn victims, oxidative stress signs have a maladaptive character. Oxidative stress is seen in blood plasma and red blood cells, accompanied by a pronounced depletion of enzyme antioxidant system reserve. The findings of the oxidative stress features may prove useful in determining a different approach to the correction of pathological conditions, such as burns and osteomyelitis ${ }^{5,25,28-30}$.

\section{ABBREVIATIONS}

AOA: antioxidant activity

DC: diene conjugates

TC: triene conjugates

ShB: Schiff bases 


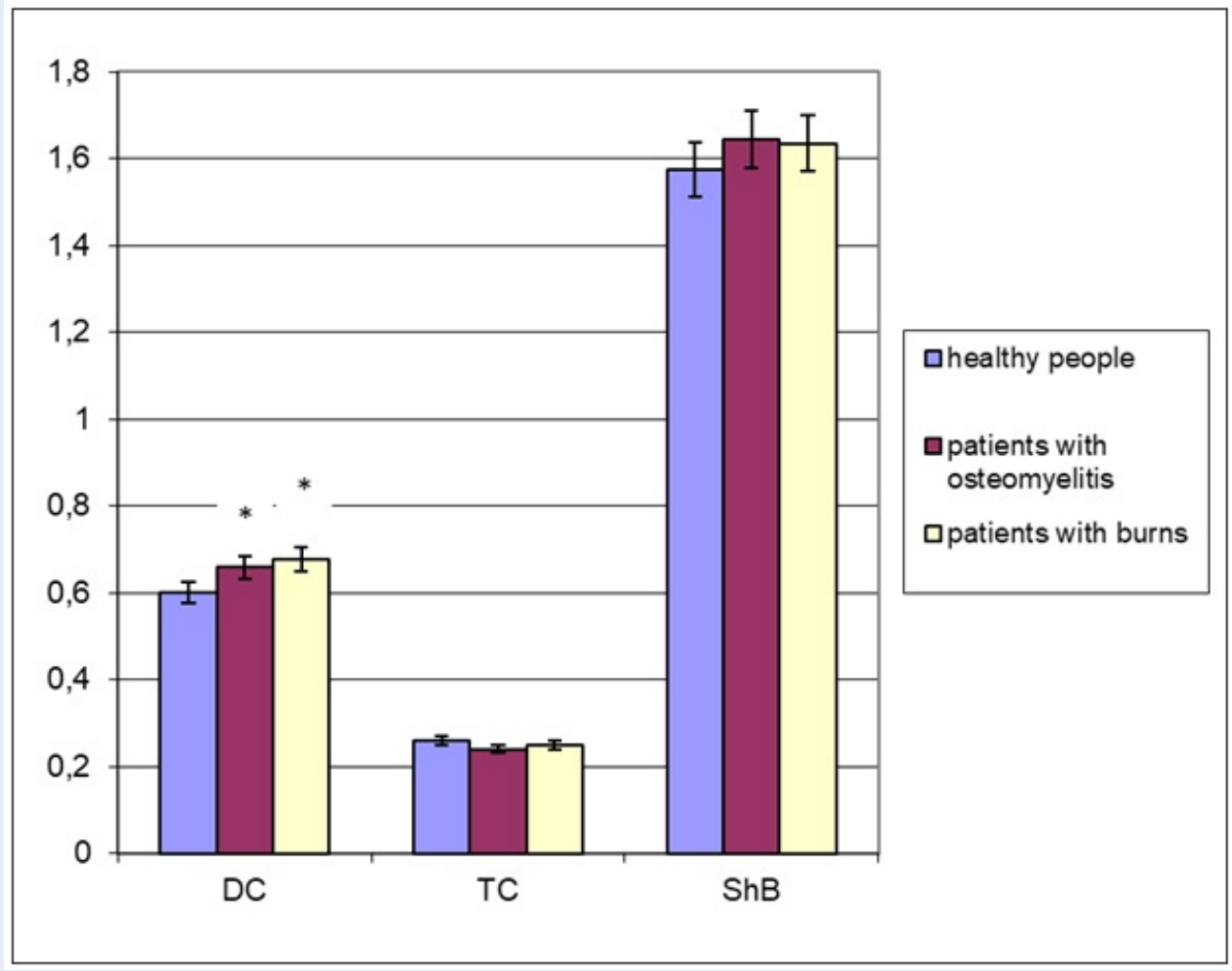

Figure 5: Level of diene (DC) and triene conjugates (TC) and Schiff bases (ShB) in blood plasma in healthy people and patients with chronic osteomyelitis and burns ("*" - level of statistical differences compared to healthy people; $p<0.05$ ).

\section{AUTHOR'S CONTRIBUTIONS}

A.K.M., V.I.Z. and A.G.S. contributed to the conceptualization and design of the study, the analysis and interpretation of data. A.S.P. carried out the selection and supervision of patients. K.L.B. and A.G.S. performed laboratory tests. They were drafting the article and revising the article critically for important intellectual content. All authors read and approved the final manuscript.

\section{FUNDING}

This article had no financial support of this faculty.

\section{AVAILABILITY OF DATA AND MATERIALS}

Data and materials used and/or analyzed during the current study are available from the corresponding author on reasonable request.

\section{ETHICS APPROVAL}

The study was approved by Local Ethic Committee of Privolzhsky Research Medical University (no. 2 from
$18 / 02 / 2018)$.

\section{CONSENT FOR PUBLICATION}

The authors hereby consents that the Publisher publishes the Work.

\section{COMPETING INTERESTS}

The authors declare that they have no competing interests.

\section{REFERENCES}

1. Azzi A, Davies KJ, Kelly F. Free radical biology - terminology and critical thinking. FEBS Lett. 2004;558(1-3):3-6;Available from: https://doi.org/10.1016/S0014-5793(03)01526-6.

2. Bartz RR, Piantadosi CA Clinical review: oxygen as a signaling molecule. Crit. Care 2010;14(5):234;PMID: 21062512. Available from: https://doi.org/10.1186/cc9185.

3. Liochev SI. Reactive oxygen species and the free radical theory of aging. Free Radic Biol Med. 2013;60:1-4. doi 10.1016/j.freeradbiomed.2013.02.011;PMID: 23434764. Available from: https://doi.org/10.1016/j.freeradbiomed.2013.02. 011.

4. Pomatto LCD, Davies KJA. Adaptive homeostasis and the free radical theory of ageing. Free Radic Biol Med. 2018;124:420430;PMID: 29960100. Available from: https://doi.org/10.1016/ j.freeradbiomed.2018.06.016 


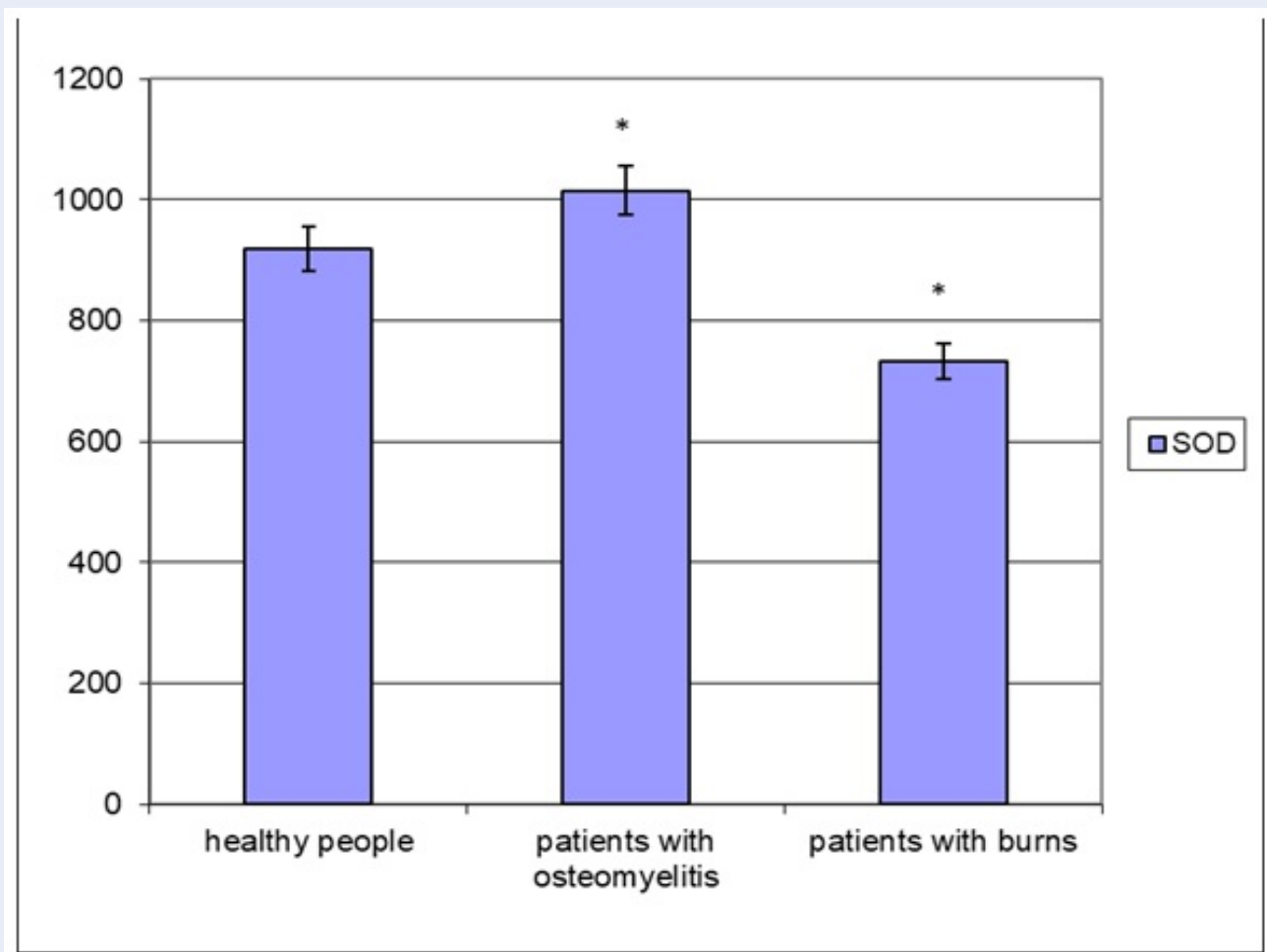

Figure 6: Superoxide dismutase activity in erythrocytes in healthy people and patients with chronic osteomyelitis and burns ("**" - level of statistical differences compared to healthy people; $p<0.05$ ).

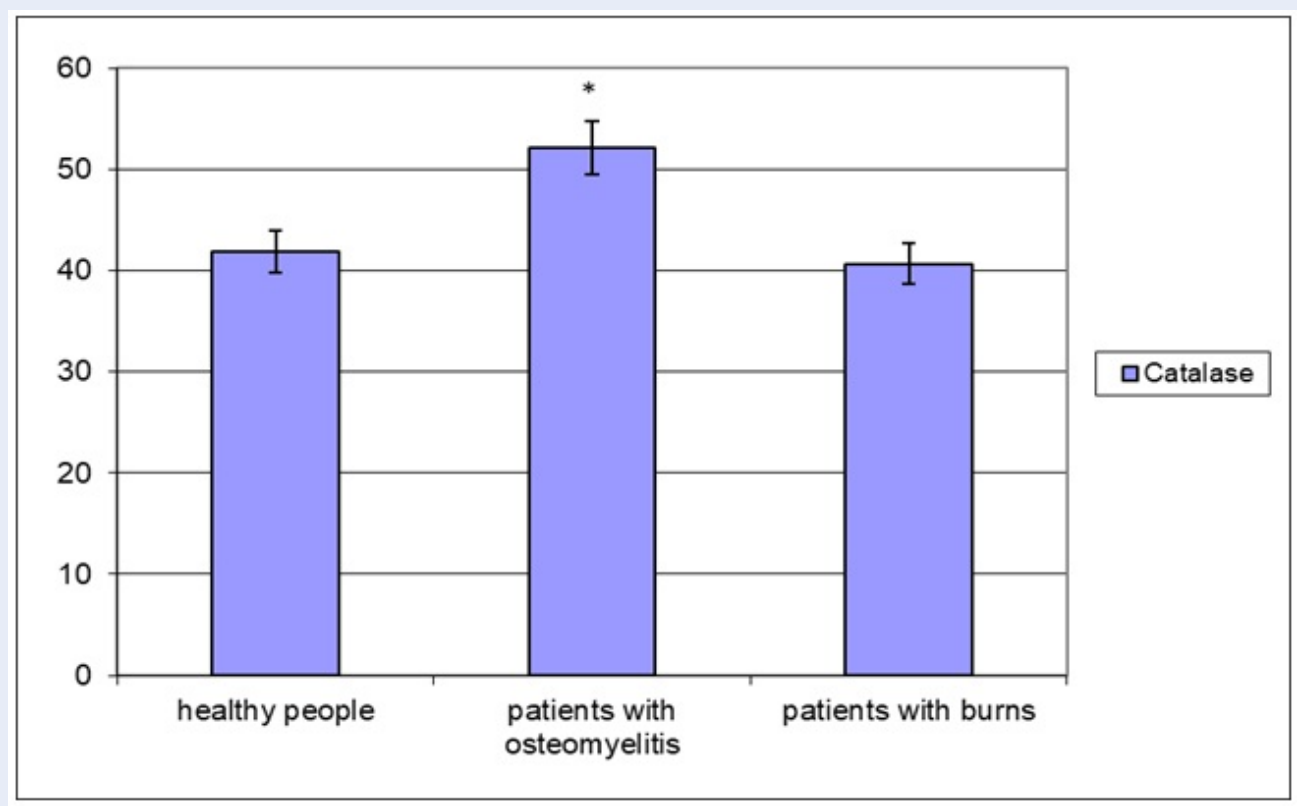

Figure 7: Catalase activity in erythrocytes in healthy people and patients with chronic osteomyelitis and burns ("*" - level of statistical differences compared to healthy people; $p<0.05$ ). 
5. Martusevich AK, Soloveva AG, Martusevich AA, Karuzin KA, Peretyagin SP. Bioradical homeostasis as new complex parameters of different biological systems. Journal of Integrated OMICS. 2020;10(2):29-32;Available from: https://doi.org/10. 5584/jiomics.v10i2.328.

6. Pryor WA, Houk KN, Foote CS, Fukuto JM, Ignarro LJ, Squadrito GL, Davies KJ. Free radical biology and medicine: it's a gas, man! Am J Physiol Regul Integr Comp Physiol. 2006;291(3):R491-511;PMID: 16627692. Available from: https: //doi.org/10.1152/ajpregu.00614.2005.

7. Tyurina $Y Y$, Tyurin VA, Anthonymuthu $T$, Amoscato $A A$, Sparvero LJ, Nesterova AM, Baynard ML, Sun W, He R, Khaitovich P, Vladimirov YA, Gabrilovich DI, Bayır $H$, Kagan VE. Redox lipidomics technology: Looking for a needle in a haystack. Chem Phys Lipids. 2019;221:93-107;PMID: $30928338 . \quad$ Available from: https://doi.org/10.1016/j.chemphyslip.2019.03.012.

8. Mladenovic DA, et al. Dietary Restriction and Oxidative Stress: Friends or Enemies? Antioxid Redox Signal. 2021;34(5):421438;PMID: 32242468. Available from: https://doi.org/10.1089/ ars.2019.7959.

9. Singh A, Kukreti R, Saso L, Kukreti S. Oxidative Stress: A Key Modulator in Neurodegenerative Diseases. Molecules. 2019;24(8):1583;PMID: 31013638. Available from: https://doi. org/10.3390/molecules24081583.

10. Taysi S, Tascan AS, Ugur MG, Demir M. Radicals, Oxidative/Nitrosative Stress and Preeclampsia. Mini Rev Med Chem. 2019;19(3):178-193;PMID: 30324879. Available from: https: //doi.org/10.2174/1389557518666181015151350.

11. Tejero J, Shiva S, Gladwin MT. Sources of Vascular Nitric Oxide and Reactive Oxygen Species and Their Regulation. Physiol Rev. 2019;99(1):311-379;PMID: 30379623. Available from: https://doi.org/10.1152/physrev.00036.2017.

12. Griendling KK, FitzGerald GA. Oxidative stress and cardiovascular injury. Part I: basic mechanisms and in vivo monitoring of ROS. Circulation 2003;21:1912-6;PMID: 14568884. Available from: https://doi.org/10.1161/01.CIR.0000093660.86242.BB.

13. Jones DP. Radical-free biology of oxidative stress. Am J Physiol Cell Physiol. 2008;295(4):C849-68;PMID: 18684987. Available from: https://doi.org/10.1152/ajpcell.00283.2008.

14. Riley PA. Free radicals in biology: oxidative stress and the effects of ionizing radiation. Int J Radiat Biol. 1994;65(1):2733;PMID: 7905906. Available from: https://doi.org/10.1080/ 09553009414550041.

15. Sies H. Oxidative stress: a concept in redox biology and medicine. Redox Biol. 2015;4:180-3;PMID: 25588755. Available from: https://doi.org/10.1016/j.redox.2015.01.002.

16. Guo Q, Li F, Duan Y, Wen C, Wang W, Zhang L, Huang R, Yin Y. Oxidative stress, nutritional antioxidants and beyond. Sci China Life Sci. 2020;63(6):866-874;PMID: 31705360. Available from: https://doi.org/10.1007/s11427-019-9591-5.

17. Rahal A, Kumar A, Singh V, Yadav B, Tiwari R, Chakraborty S, Dhama K. Oxidative stress, prooxidants, and antioxidants: the interplay. Biomed Res Int. 2014;2014:761264;PMID: 24587990. Available from: https://doi.org/10.1155/2014/761264.

18. Martusevich AK, Dmitrochenkov AV, Razumovsky AV, Galova EA. Possibilities of monitoring the physical and chemical prop- erties of biological fluids in combustiology. Medicine (Russia). 2018;1:149-160;Available from: https://doi.org/10.29234/ 2308-9113-2018-6-1-149-160.

19. Mutwedu VB, Nyongesa AW, Oduma JA, Kitaa JM, Mbaria JM. Thermal stress causes oxidative stress and physiological changes in female rabbits. J Therm Biol. 2021;95:102780;PMID: 33454048. Available from: https://doi.org/10.1016/j.jtherbio.2020.102780.

20. Parihar A, Parihar MS, Milner S, Bhat $S$. Oxidative stress and anti-oxidative mobilization in burn injury. Burns. 2008;34(1):617;PMID: 17905515. Available from: https://doi.org/10.1016/j. burns.2007.04.009.

21. Roshangar L, Soleimani Rad J, Kheirjou R, Reza Ranjkesh M, Ferdowsi Khosroshahi A. Skin Burns: Review of Molecular Mechanisms and Therapeutic Approaches. Wounds. 2019;31(12):308-315;.

22. Chen DS, Cao JG, Zhu B, Wang ZL, Wang TF, Tang JJ. Baicalin Attenuates Joint Pain and Muscle Dysfunction by Inhibiting Muscular Oxidative Stress in an Experimental Osteoarthritis Rat Model. Arch Immunol Ther Exp (Warsz). 2018;66(6):453461;PMID: 30076457. Available from: https://doi.org/10.1007/ s00005-018-0518-6.

23. Grbic R, Miric DJ, Kisic B, Popovic L, Nestorovic V, Vasic A. Sequential analysis of oxidative stress markers and vitamin C status in acute bacterial osteomyelitis. Mediators Inflamm. 2014;2014:975061;PMID: 25180026. Available from: https: //doi.org/10.1155/2014/975061.

24. Jyoti A, Singh S, Mukhopadhyay B, Gavel R, Mishra SP. Free radicals and antioxidant status in chronic osteomyelitis patients: a case control study. J Clin Diagn Res. 2015;9(4):BC0810;PMID: 26046017. Available from: https://doi.org/10.7860/ JCDR/2015/11950.5781.

25. Martusevich AK, Razumovsky AV, Soloveva AG, Ezhevskaya AA, Peretyiagin SP. The study of postburn metabolic rehabilitation with natural NO donor. Asian Journal of Biochemical and Pharmaceutical Research. 2016;6(3):14-21;.

26. Masch JL, Bhutiani N, Bozeman MC. Feeding During Resuscitation After Burn Injury. Nutr Clin Pract. 2019 Oct;34(5):666671;PMID: 31441131. Available from: https://doi.org/10.1002/ ncp. 10400 .

27. Moreira E, Burghi G, Manzanares W. Update on metabolism and nutrition therapy in critically ill burn patients. Med Intensiva. 2018;42(5):306-316;PMID: 28951113. Available from: https://doi.org/10.1016/j.medin.2017.07.007.

28. Martusevich AK, Peretyagin SP, Ruchin MV, Struchkov AA. Ozone therapy in patients with burn disease. J. Biomedical Science and Engineering. 2018;11(2):27-35;Available from: https: //doi.org/10.4236/jbise.2018.112003.

29. Vassalle C, Maltinti M, Sabatino L. Targeting Oxidative Stress for Disease Prevention and Therapy: Where Do We Stand, and Where Do We Go from Here. Molecules. 2020;25(11):2653;Available from: 10.3390/molecules25112653.

30. Yang B, Chen Y, Shi J. Reactive Oxygen Species (ROS)-Based Nanomedicine. Chem Rev. 2019;119(8):4881-4985;PMID: 30973011. Available from: https://doi.org/10.1021/acs. chemrev.8b00626. 